BULLETIN Bulletin hispanique

HISPANIQUE Université Michel de Montaigne Bordeaux

118-2 | 2016

Varia

\title{
Las instituciones culturales, el arte y el mundo clásico en el Viaje a Italia de Moratín
}

Rafael Alarcón Sierra

\section{(2) OpenEdition}

Journals

Edición electrónica

URL: http://journals.openedition.org/bulletinhispanique/4527

DOI: 10.4000/bulletinhispanique.4527

ISSN: 1775-3821

Editor

Presses universitaires de Bordeaux

Edición impresa

Fecha de publicación: 15 diciembre 2016

Paginación: 517-534

ISBN: 979-10-300-0125-9

ISSN: 0007-4640

Referencia electrónica

Rafael Alarcón Sierra, « Las instituciones culturales, el arte y el mundo clásico en el Viaje a Italia de Moratín », Bulletin hispanique [En línea], 118-2 | 2016, Publicado el 15 diciembre 2019, consultado el 30 diciembre 2019. URL : http://journals.openedition.org/bulletinhispanique/4527 ; DOI : 10.4000/ bulletinhispanique. 4527 


\title{
Las instituciones culturales, el arte y el mundo clásico en el Viaje a Italia de Moratín
}

\author{
Rafael Alarcón Sierra \\ Universidad de Jaén
}

Cet article analyse les annotations de Leandro Fernández de Moratín à son voyage en Italie (1793-1796) relatives aux institutions culturelles, aux antiquités classiques et aux œuvres d'art. Bien que Moratín reproduise les idéaux normatifs de l'esthétique néoclassique, son écriture est personnelle, libre, moderne et ironique.

Mots-clés: Leandro Fernández de Moratín, voyage en Italie, institutions culturelles, critique d'art.

Este artículo analiza las anotaciones que Leandro Fernández de Moratín realiza en su Viaje a Italia (1793-1796) relativas a las instituciones culturales, las antigüedades clásicas y las obras de arte. Aunque Moratín reproduce los ideales normativos de la estética neoclásica, ofrece una escritura privada, libre, irónica y moderna.

Palabras clave: Leandro Fernández de Moratín, viaje a Italia, instituciones culturales, crítica artística.

This paper analyzes the annotations performed by Leandro Fernández de Moratín to his Viaje a Italia (1793-1796) relating to cultural institutions, classical antiquities and works of art. Although Moratín reproduces the normative ideals of neoclassical aesthetics, he offers a private, free, ironic and modern writing.

Keywords: Leandro Fernández de Moratín, travel to Italy, cultural institutions, art criticism.

Z 1 capítulo quizá más tradicional de la visita a Italia en el siglo dieciocho,

L puesta ya en un segundo plano la devota peregrinación religiosa, es el que concierne al análisis de sus antigüedades clásicas y de sus obras de arte. Los libros de viaje adquieren de esta forma el aspecto de un diletante catálogo de 
piezas de museo. Sin embargo, Moratín, en los cuadernos de su Viaje a Italia (escritos entre 1793 y 1796) ${ }^{1}$, como otros autores de la segunda mitad del siglo, intenta dinamizar este aspecto insoslayable haciendo también referencias a la vida cultural italiana: bibliotecas, academias, universidades y gabinetes, sin olvidar las visitas a literatos, eruditos y sabios, para las que frecuentemente se llevaban cartas de recomendación. Sin embargo, el panorama resultante en este ámbito es más bien pobre, como veremos. Moratín lo enriquece analizando a fondo la escena teatral, aspecto que en los libros de viaje dieciochescos tenía un lugar bastante secundario; a cambio, la música, fuera del ámbito representativo, está más desatendida, pese a la supremacía italiana en toda Europa².

Moratín hace breves referencias a las Universidades de Milán, Módena, Padua y Turín. En esta última se detiene un poco más, puesto que, nos dice, «asistí a unos grados» (aunque no añade ninguna otra información al respecto ni en su diario personal ni en sus cartas), pero su opinión de ilustrado acerca del escolasticismo que presencia es muy negativa: «quién podrá llevar en paz la indiferencia con que mira el Gobierno un objeto de tal entidad, y que así consienta que la juventud estudiosa y llena de talento pierda así su tiempo y su razón en aprehender desatinos, y que en vez de promover las ciencias útiles, se enseñe y se aprehenda una algaravía ridícula [...] así se perpetúa el goticismo, la presunción y la ignorancia [...] Así hay tantos doctores y tan pocos que sepan algo ${ }^{3}$. Su comentario sobre esta ausencia de política educativa adquiere su completa dimensión si recordamos que Moratín no tenía estudios universitarios, y que sus viajes por Europa se orientaban en parte a compensar esta carencia.

Los gabinetes que visita, pese a su barniz ilustrado, sobre todo en el afán clasificatorio, todavía recuerdan a los ingenuos «cuartos de maravillas» que los viajeros mencionan en siglos precedentes, principalmente si tienen carácter privado. Así, el «célebre» gabinete del Barón de Hüpsch en Colonia (120), el confuso del palacio del Elector en Manheim (131) o el «ridículo» del Conde Rambaldo en Lendinara (373), hecho de minucias que Moratín se entretiene en enumerar irónicamente, como una parodia de los inventarios tradicionales de los libros de viaje. Más rigurosos le parecen los museos de historia natural de Florencia y Milán y el lapidario de Verona, relacionados con instituciones educativas. Aparte de relacionar sus principales objetos, Moratín siempre señala si tienen catálogo impreso.

1. Vid. R. Alarcón Sierra, «Discurso, representación y mirada en el Viaje a Italia de Leandro Fernández de Moratín», Bulletin of Spanish Studies, LXXXVI, 6, 2009, pp.747-768, y la bibliografía allí citada.

2. Vid. R. Alarcón Sierra, «El teatro en el Viaje a Italia de Moratín», en Á. Ezama et al (coord.), Aún aprendo. Estudios dedicados al profesor Leonardo Romero Tobar, Zaragoza, Prensas Universitarias de Zaragoza, 2012, pp. 483-492.

3. L. Fernández de Moratín, Viage a Italia. Ed. de Belén Tejerina, Madrid, Espasa-Calpe, 1988, pp. 525-526. Cito siempre por esta edición, poniendo a continuación, entre paréntesis, el número de página correspondiente. 
Las Academias italianas tampoco salen muy bien paradas: solo son dignas de abierto elogio la Academia Patriótica de Milán y sobre todo el Instituto de Bolonia ("que ha servido de norma a muchas célebres academias de Europa», 194). Correctas son, pese al entusiasmo que pone Moratín en intentar alabar en ellas algún mérito menor, las Academias de Bellas Artes de Parma y Génova («no parece que haya salido, hasta ahora, ningún talento superior», 503), y la de Ciencias y Bellas Letras de Mantua. Deplorable es la de Nápoles, de la que el viajero llega a decir que «no existe sino en la Guía de Forasteros», ya que "no hay libros, no hay instrumentos, no se celebran juntas» (320-321).

Algo más de atención dedica Moratín a las principales bibliotecas de Italia, pero, pese a su memorial a Godoy desde Bolonia en septiembre de 1793, donde aduce como mérito el estudio de estos establecimientos para conseguir un puesto de bibliotecario en Madrid ${ }^{4}$, su conocimiento de ellos es superficial. Por su diario personal sabemos que no dedicó mucho tiempo a su consulta. Solo estuvo varias veces, en sus distintas estancias en la ciudad, en la Vaticana de Roma y en la Ambrosiana de Milán. Como la mayoría de los viajeros del XVIII, se limita a hacer una breve reseña sobre ellas: cantidad de volúmenes que poseen, índices o catálogos impresos, en caso de haberlos, facilidad de acceso y de consulta, y listado de sus colecciones, libros y manuscritos principales, que son observados y enumerados como si se tratara de un museo (por ejemplo, en Turín: «Entre los manuscritos, de que hay impreso un catálogo, hay algunos mui apreciables [...] la Historia Natural de Plinio, lleno de ornatos delicadísimos y miniaturas [...] la Comedia, de Dante, con miniaturas mui bellas [...] un libro de oraciones [...] un prontuario de Julio Romano [...] una grande obra de historia natural [...] impresos [...] una Políglota de Arias Montano [...] un libro chino de las obras de Confuncio», 523-524; o en la Ambrosiana: «la traducción de las Antigüedades de Josefo, por Rufino [...] un Virgilio, en pegamino con varias notas marginales del Petrarca [...] un curioso manuscrito de la Vida de los papas por Martín Polono, que ha servido a muchos de autoridad para dar por cierta la existencia de la papisa Juana [...] Los manuscritos y dibujos de Leonardo Vinci», 544-546). Destaca principalmente las bibliotecas de Brera y la Ambrosiana de Milán, la Farnese en Parma, la Vaticana de Roma (coincide con el abate Andrés en criticar las dificultades para consultarla, 339-340, 572574), la pública de Ferrara y la de la Universidad de Turín.

Las visitas a eruditos y literatos locales muchas veces eran una atracción más del viaje, casi al mismo nivel que la contemplación de una escultura o un cuadro, sobre todo si no tenían ninguna relación inmediata con las actividades habituales del viajero. Otras veces, estas personas servían de guía, como ocurre con los profesores que acompañan a Moratín en la visita a Universidades y Academias. A veces, el conocimiento se basaba en una relación previa, como ocurre con Bernascone y Conti, amigos del padre de Moratín y tertulianos en la fonda madrileńa de San Sebastián, o en una nacionalidad compartida, como

4. L. Fernández de Moratín, Epistolario de Leandro Fernández de Moratín. Ed. de R. Andioc, Madrid, Castalia, 1973, n 42, pp. 158-160. 
ocurre con los exjesuitas y colegiales españoles de Bolonia (a los que dedicará una oda, así como al rector del colegio de San Clemente) $)^{5}$, Ferrara y Mantua. Visita de verdadero interés para el viajero es la que realiza en 1793 al célebre impresor Bodoni, que tres años después iba a editar La Comedia Nueva y a mantener correspondencia con él, en español e italiano.

Moratín no dedica a estas visitas más que dos o tres líneas, casi siempre encabezadas por expresiones del tipo "fui a ver», «fui a visitar», nunca reproduce su conversación, y lo más interesante es el rápido y certero retrato que hace de los personajes. Así, Bodoni es «hombre de excelente carácter, joven, de bella presencia, gran viveza, instruido, amable» (181); el abate Parini, «hombre de más de cincuenta años, alto, estropeado de piernas, gesto avinagrado» (163164); Manuel Aponte, «hombre muy instruido, [de exquisito gusto en la poesía], modesto, festivo, amable» $(193)^{6}$; el Conde Rambaldo, Oficial de artillería, «joven, vivaracho, afectadísimo, de buen ingenio y agasajador» (373); el abate Fortis, «físico estimable, humanista, crítico terrible, que destroza con la pluma y con la lengua, gracioso en la combersación, alto, moreno, ojos negros, cejas pobladas, rostro expresivo, voz de hierro» (390). Finalmente, cuando visite a «la famosa Corila Olímpica, coronada, muchos ańos ha, en el Capitolio por su mérito poético», y poco después modelo para la Corinne de Madame de Staël (que le hará morir joven), encontrará Moratín «una viejecilla ridícula, arrugada, pálida, canosa, tabacosa, sin dientes, guiñando el ojo derecho, con tos y dolores en las piernas, mui habladorcilla y de mucho espíritu, que es lo único que la queda; lo demás lo arrebató inexorable el tiempo» (565-566). Este es uno de sus mejores retratos a vuelapluma, visión casi elegíaca del tempus fugit donde el escritor muestra su habilidad para captar en dos rasgos el carácter del personaje descrito, amén de su perfecto manejo de los diminutivos en las enumeraciones.

Mucho mayor espacio dedica el viajero en su diario a las innumerables obras de arte que atesora Italia. Los libros de viaje habían ayudado a asentar en el siglo XVIII lo que podemos llamar una crítica de arte literaria en escritores que no eran necesariamente especialistas en la materia, como es el caso de Moratín. Antes de este siglo, no era habitual que un profano juzgara con cierta seguridad y conocimiento diversas obras de arte, haciendo referencia a las técnicas, a los períodos y a las escuelas, y utilizando términos especializados como invención, composición, expresión, diseño, colorido, gracia, etc. En sus análisis, aunque Moratín reproduce los ideales normativos de la estética neoclásica ${ }^{7}$ (desde cuya

5. Vid. B. Tejerina, «Leandro Fernández de Moratín y el Colegio de España» [«El cardenal Albornoz y el Colegio de España»], Studia Albornotiana, XXXVII, 1979, pp. 625-650.

6. El texto entre corchetes aparece tachado en el original.

7. Vid., como bibliografía general, I. Henares Cuéllar, La teoría de las artes plásticas en España en la segunda mitad del siglo XVIII, Granada, Universidad, 1977, F. J. León Tello y V. Sanz Sanz, Tratados neoclásicos españoles de pintura y escultura, Madrid, Universidad Autónoma, 1980; Simón Marchán Fiz, La estética en la cultura moderna: de la Ilustración a la crisis del estructuralismo, Madrid, Alianza, 1987 (sin olvidar R. Wellek, Historia de la critica moderna (1750-1950). Segunda mitad del siglo XVIII, Madrid, Gredos, 1969); y Andrés Úbeda de los Cobos, «Literatura 
perspectiva histórica han de ser tenidos en cuenta), también ofrece juicios de gusto e impresiones personales, como veremos, que en contrapartida caracterizan implícitamente al yo textual.

Antes de emitir sus juicios, son frecuentes sus avisos y protestas de no ser un experto en la materia (aunque esta falsa modestia no le impida en absoluto mostrar su parecer, siempre con rotundidad): «a mí, que no entiendo de arquitectura...» (166); «Si mi opinión valiese...» (522); «Si es lícito a quien no profesa tan difíciles artes dar su opinión sobre el estado actual de ellas...» (582); «Si es lícito, quando se ignoran los principios de un arte, exponer su propia opinión y juzgar por las sensaciones que uno recibe...» (464).

Los valores artísticos de los que parte Moratín son los propios de la estética clásica: el ideal es la imitación del arte grecolatino, en arquitectura y escultura, y del renacentista en pintura. En el primer caso, sigue implícitamente la interpretación del arte antiguo que habían esparcido Jakob Burckhardt y Winckelmann por toda Europa (y Antonio Rafael Mengs en España). En el segundo, concibe la pintura italiana como una progresión histórica constante en técnica, gusto y perfección que produce una serie de maestros indiscutibles, tal y como ya había sido interpretada por Vasari. Todo lo demás es rechazable, tanto los primitivos italianos, que solo valen como curiosidades históricas, como el extravagante barroco.

Moratín establece en sus comentarios una serie de axiomas generales. En primer lugar, el objeto del arte es la imitación de la naturaleza, pero no de forma directa sino idealizada, no tal cual es sino tal y como debería ser (idea clásica de la imitación de la naturaleza -de tradición aristotélica- y de la belleza ideal -de raíz platónica-, en línea con las concepciones estéticas neoclásicas de Winckelmann y Mengs, que había reafirmado como objeto del arte su amigo Esteban de Arteaga en las Investigaciones filosóficas sobre la belleza ideal, 1789 ${ }^{8}$ ). Ello se ve claramente en su comentario ante la Venus de Urbino de Tiziano, que sigue un tópico clásico repetido tanto por Luzán como por Arteaga -quien se refiere a la misma pintura- ${ }^{9}$ : «dicen que es el retrato de su dama. [...] Pero es

artística», en F. Aguilar Piñal (ed.), Historia literaria de España en el siglo XVIII, Madrid, Trotta / CSIC, 1996, pp. 1029-1064.

8. Vid. Esteban de Arteaga, La belleza ideal, ed. M. Batllori, Madrid, Espasa-Calpe, 1972, pp. 49, 69 y 122.

9. Cf. Cicerón, De inventione, lib. II: «Neque enim putauit [Zeuxis] omnia, quae quaereret ad uenustatem, uno in corpore se reperire posse ideo, quod nihil simplici in genere omnibus ex partibus perfectum natura expoliuit». I. de Luzán, La Poética, lib. I, cap. VIII: «la pintura, o representa algún hombre como es, lo que propriamente se llama retratar, o le forma de su idea y capricho, según lo verisímil, como hizo Zeuxis, que, para pintar la famosa Helena, no se contentó con copiar la belleza particular de alguna mujer, sino que juntando todas las más hermosas de los crotoniates, tomó de cada una aquella parte que le pareció más perfecta, y así formó, más que el retrato de Helena, el dechado de la misma hermosura» (Ed. de R. P. Sebold, Madrid, Labor, 1977, p. 170); E. de Arteaga, La belleza ideal, VI: «Zeuxis, que, encargado por los crotoniatas de pintar un retrato de Helena, hizo traer delante de sí las doncellas más hermosas de la ciudad para sacar del conjunto de ellas las perfecciones que sabía no podían hallarse en un solo individuo»; XI: «un idealista, poniéndome delante de los ojos la Venus de Médicis o la de 
error, su dama podría tener aquella cara, aquellas manos o aquellos muslos, pero aquella forma total no ha existido jamás sino en la fantasía del pintor; la naturaleza le ofreció separados los obgetos, como haze siempre; él supo formar de muchas partes hermosas un todo perfecto, y éste es el gran secreto de los buenos artífices. Esto es lo que se llama invención, de aquí resulta aquella belleza que, sin dexar de ser natural, jamás se encuentra tal en los obgetos que la naturaleza nos ofrece, este es el don concedido a las artes» (203). Por otra parte, "Quando el arte quiere suplir a la naturaleza, solo produce extravagancias» (242).

En segundo lugar, «el último esfuerzo de las artes» es provocar «la ilusión», es decir, que la ficción sea tal que pueda «equivocarse con la verdad misma» (384). Es la misma idea que va aplicar a su visión del teatro. Para discernir el verdadero mérito, hay que analizar "las ideas de la imitación, de la invención y de la belleza» (586). La normatividad es importante, porque «Hay cierta rutina en las artes, de la qual no es fácil apartarse sin tropezar en graves incombenientes» (278). Sin embargo, esta es la única sujeción a la que debería someterse el artista, que por lo demás debe «poder dar a su fantasía la libertad» que necesite, ya que "Quando los artífices sujetan la composición de sus obras al gusto de quien las paga, el ingenio, oprimido, produce cosas triviales, y tal vez ridículas» (458-459). Moratín se queja amargamente (y quizá piensa en su posición ante Godoy) de que «las artes, envilecidas y venales tal vez, se ocupan en perpetuar la memoria de quien no debió existir», y por ello hace un ruego a los artistas: «Pintores, escultores, poetas, eternizad la virtud, no aduléis la ignorancia ni el vicio y entonces las artes se llamarán, con razón, divinas» (368). Por último, «lo inútil es siempre malo» (387), y «el verdadero carácter de las obras más bellas» es «sencillez, hermosura y verdad» (247).

$\mathrm{Al}$ aplicar estos criterios generales a las manifestaciones artísticas concretas, todo resulta mucho más complejo. La necesidad de motivar expresivamente sus gustos en confrontación con las obras hace que el yo textual adquiera un gran relieve, pues involuntariamente se ve definido y retratado en sus preferencias y juicios de valor. La descripción siempre va acompañada de una evaluación, que retrata social e intelectualmente al sujeto que la emite. Pero además, la crítica de arte de Moratín también está cargada de manifestaciones afectivas, principalmente cuando rechaza o admira con vehemencia la obra que describe, lo que propicia una mayor extraversión de los sentimientos y una apariencia de mayor confianza e intimidad hacia su hipotético lector. En el primer caso, el escritor emplea un tono informal y distendido, lleno de rasgos coloquiales y hasta vulgares, humorísticos o irónicos (inmejorable ejemplo de ello es lo que anota en la Iglesia de San Antonio de Padua: "En una de las paredes del coro hay un retrato de San Antonio, que pasa por auténtico, el qual Santo es blanco, rubio, ojos garzos, de buena cara, ni feo ni virolento, como yo, según quieren

Ticiano, me enseña en compendio las perfecciones de toda la especie, y hasta dónde se extiende el poder de la naturaleza en la harmonía y proporción del cuerpo mujeril» (ed. cit., pp. 71 y 127, respectivamente). 
algunos, ni tan bonito y graciosito como creen mis tías», 392). En el segundo, se aproxima a la expresión sensible de lo poético, lo espiritual o lo verdadero.

Lo vamos a ver en sus análisis concretos. Moratín reconoce que, pese a sus intentos de recuperar el buen gusto, «el siglo de las academias, de los preceptos y de la crítica no es el siglo de las artes» (508). En arquitectura, la antigüedad romana es el modelo, por sus valores de simetría, proporción, armonía, ligereza, sencillez, orden, sobriedad, elegancia, belleza y utilidad. Lo declara explícitamente al analizar los palacios de Vicenza: «el buen gusto, nacido del conocimiento del arte», «no consiste en copiar por líneas y escrúpulos los cinco órdenes del Vignola, sino en formar un todo con aquellas partes y darlas tal simetría y proporción, que juzgue el que lo ve que no pudiera hazerse de otra manera. Proporción, éste es el gran secreto de la arquitectura; de aquí nace aquella armonía de partes, aquella ligereza, aquel orden, aquella sobriedad unida a la elegancia, y aquella belleza unida a la utilidad, que hazen tan difícil el arte» (387). Y en Roma, cuando en muchos edificios observa la falta «de aquella sobriedad, de aquella encantadora sencillez, de aquella proporción de partes, de aquella harmonía en el todo que es el mérito verdadero de los grandes artífizes» (580).

Todo lo que no cumple estas normas es rechazable, tanto el gótico como el barroco, entendidos como desviaciones del buen gusto, puesto que "el olvido de los buenos principios y el desenfreno de la imaginación [...], apartándose de los preceptos, concibe solo despropósitos» (454-455). Gótico y barroco (denominación que todavía no existe en tiempos de Moratín) son en muchas ocasiones términos casi intercambiables, de significación puramente peyorativa, y que no designan un estilo histórico bien definido, sino un conjunto de obras de diferentes épocas que no cumplen las reglas. Lo gótico es lo medieval, el olvido de los principios clásicos por desconocimiento e ignorancia ${ }^{10}$, y lo barroco es lo extravagante, lo recargado, lo ornamental. Lo contrario de ambos es lo antiguo, lo clásico. Al igual que Ponz, Moratín hace coloquialmente equiparable lo barroco a lo churrigueresco. En Turín, el Palacio de Carignan, «es digno de Churriguera, por las muchas garambaynas y triquitraques de que está lleno» (519); en Roma, el Palacio Doria, «no es indigno de nuestro abominado Churriguera» (579).

En su rechazo de las desviaciones, Moratín pasa de la crítica razonada (por ejemplo, de los templos barrocos de Nápoles: «la arquitectura, en general, recargada de ornatos, que destruyen la hermosa simplicidad de sus órdenes, y

10. Con todo, en las Apuntaciones sueltas de Inglaterra hay, al menos en dos ocasiones, una valoración positiva del arte gótico: «Hay en esta iglesia [la catedral de Winchester] varios sepulcros de prelados y otros grandes personajes, y en algunos de ellos es de admirar la delicadeza del estilo gótico» (II, 8, ms. 5891 de la Biblioteca Nacional de Madrid, fol. 35v); «La iglesia del palacio [de Windsor] es de gusto gótico: muy clara, alegre, limpia y desembarazada» (II, 8, ibid., fol. 39v); en Obras completas de Nicolás y Leandro Fernández de Moratín. Ed. J. Pérez-Magallón, Madrid, Cátedra, 2008, vol. II, pp. 959 y 963. Vid. R. Alarcón Sierra, «Las Apuntaciones sueltas de Inglaterra de Leandro Fernández de Moratín: libro de viajes y fundación de una escritura moderna», Bulletin Hispanique 109, 1, junio 2007, pp. 157-186. 
la dan un carácter profano y teatral, harto distante de la magestuosa sencillez que es propia del templo», 271-272, o del Palacio Real de Capodimonte: «en la parte que está concluida, anuncia demasiado la corta habilidad de su artífice sin proporción, sin ligereza, sin elegancia; todo es mazacote, extravagante y rudo", 269), al rotundo y desvergonzado coloquialismo, con el que muestra extrovertidamente el énfasis de su desprecio. Así, en Lucerna, «El cimenterio de la Cathedral es uno de los más charrangueros que he visto» (148); en Milán, la iglesia de San Lorenzo "parece una jaula» (166); en Padua, el claustro de la Casa Ferrari, es «digno de qualquier aprendiz de pastelero» (391-392), o «En la Iglesia de Padres Servitas pueden ir a ver un grande altarón de mármoles los que gusten de galimatías y febus arquitectónicos» (399).

Pocos son los elogios completos a las obras contemporáneas, pues, como reconoce el propio Moratín, «en Roma no se ve todavía en arquitectura una obra moderna que anuncie inteligencia y gusto» (582). Solo la encontrará en Turín, en la capilla del Ospedale Maggiore di San Giovanni: «buen plan, buenos ornatos, sencilla y elegante, sin pesadez, sin confusión, sin travesuras ridículas» (522).

En cuanto a la escultura, la "superioridad de los antiguos» (251), es decir, del clasicismo grecorromano (teoría de la noble simplicidad del arte griego según Winckelman), es un criterio indiscutible: «hay muy pocas obras modernas que merezcan citarse» (455). Sin embargo, en su preferencia por la escultura dramática, la que es capaz de plasmar movimiento y patetismo en la expresión, Moratín muestra estar más cerca del periodo helenista que de las formas más puras y simples del clasicismo griego. Moratín se pregunta «Por qué los ropages de nuestras estatuas modernas no se parecen a los de las antiguas", y lo mismo ocurre con sus «actitudes», "tan naturales, sin dexar de ser expresivas» (202). Ante las esculturas de Apolo, Antinoo o el Laooconte del Museo Vaticano, su juicio es lo suficientemente expresivo: «Si un artífice puede ver tales objetos sin admiración, sin entusiasmo, sin inflamarse en generosa embidia, no pase adelante, arroje los cinceles; ni siente, ni imagina, ni nació para cultivar artes tan bellas» (340-341).

Frente a ellas, "Los buenos escultores del siglo XVI no manifestaron ciertamente en sus obras un gran fuego de invención; pecan las mejores de ellas en desmayadas y frías» y de «una regularidad lánguida e insignificante», aunque al menos eso las libró de no cometer «disparates atrevidos; su timidez los hizo arreglados y exactos en la imitación» (581). Miguel Ángel destaca por encima de todos, pero, aunque hoy nos pueda sorprender, Moratín le pone reservas: «dotado de un gran talento, dio a sus figuras movimiento y expresión, que muchas veces peca en caricatura y violencia» (581). Los viajeros del siglo XVIII, como por ejemplo el presidente Charles de Brosses en sus Lettres d'Italie, le suelen adjudicar defectos y falta de "gracia», término algo impreciso con el que hacen referencia a aquel encanto que cautiva y seduce al espectador. El «incorrecto y admirable Bernini» estuvo «lleno de fantasía y falto de gusto» (581), y luego, la corrupción y la decadencia fue general en toda Europa. 
Los escultores modernos, «No sé si por falta de ingenio o por reflexión», ya se han apartado «de la extravagante escuela» (la barroca), pero entre ellos Moratín solo encuentra un valor superior, con unas dimensiones que hoy en día quizá parezcan excesivas: «El veneziano Antonio Canova, cuyas obras, superiores a las del celebrado Miguel Ángel y comparables, tal vez, a las que hoy se admiran de la antigua Grecia, bastan a inmortalizar su nombre y su siglo, es el único, a mi entender, que haya sabido reunir la expresión, la gracia, la fuerza, la belleza, la simplicidad» (583-584).

¿Qué es lo que Moratín y su siglo vieron en Canova, por encima incluso de Miguel Ángel? Principalmente, amén de la regularidad y docilidad formal y un espíritu y un sentimiento afín a su tiempo, la estética de la inminencia del movimiento y la expresión: el engaño y la ilusión de los sentidos, según el cual las figuras parece que están vivas, que son de carne y hueso, que van a moverse de un momento a otro. Bien a las claras lo descubre cuando en la Iglesia de San Pedro razona su preferencia por el sepulcro de Clemente XIII de Canova antes que por la Pietà de Miguel Ángel:

lo que, a mi entender es superior a todas [las esculturas] aunque se cuente entre ellas el célebre grupo de mármol de la Virgen con su hijo difunto, hecho por Miguel Ángel, donde entre cosas muy buenas se hallan grandes defectos, es el sepulcro de Clemente 13 executado por Antonio Canova, escultor veneciano, el primero de Italia, y por consecuencia, de Europa [...] el Papa está representado de rodillas haciendo oración, en actitud tan expresiva, con tal verdad y sencillez, ya en el rostro, ya en la postura de las manos, ya en la distribución y pliegues de la vestidura, que si de repente se moviese, no se admiraría el movimiento. [...] Sobre el zócalo hay dos leones de gran tamaño en guarda del sepulcro; el uno parece que duerme [...] el otro parece que acaba de alzar la cabeza habiendo sentido ruido de gente, mira con ojos terribles, y es de temer que, si uno da un paso más, se levante. Hay tal maestría en la actitud, en la expresión de estos animales, tal verdad y ligereza de cincel, que no es posible mirarlos sin temor (335-336)

En cuanto a la pintura, ni los antiguos, ni los modernos, sino el apogeo del Cinquecento clásico y las cuatro escuelas principales: la corrección y el dibujo de la de Florencia (Miguel Ángel, Volterra, Andrea del Sarto), el colorido de la de Venecia (Tiziano, Tintoretto, Veronés), la elegancia y armonía de la de Roma (Rafael, Julio Romano, Aníbal Caracci) y el eclecticismo manierista de la de Lombardía y Bolonia (Correggio, Caracci, Guido Reni, Guercino). Moratín aprecia principalmente las escuelas veneciana y romana, y a sus pintores ya citados. Sus preferencias son, en la primera, Tiziano y sobre todo el Veronés, y en la segunda, por supuesto, Rafael, cuyo genio no se discute en el XVIII, al contrario que el de Miguel Ángel, que tampoco le convence en su faceta pictórica (El Juicio Final de la Capilla Sixtina «admira y no deleyta», 339). También citará varias veces a Caravaggio: el primer exponente del barroco, que, como a Moratín, sorprende a numerosos viajeros de finales del siglo XVIII por sus efectos emotivos.

En las pinturas romanas halladas en las excavaciones de Pompeya y Herculano, que juzga con los mismos criterios que a la pintura moderna, 
Moratín escribe que "pueden notarse a los antiguos los siguientes defectos: $1^{\circ}$ Errores clásicos de perspectiva. $2^{\circ}$ Poca inteligencia en graduar las luces para expresar la cercanía o distancia recíproca de los obgetos. $3^{\circ}$ Ningún arte en agrupar las figuras. $4^{\circ}$ Poco uso de los escorzos, defecto que, unido al anterior, da a la composición una frialdad y languidez insufrible» (250). No por ello deja de ponderar su valor como testimonio histórico, pero «si prescindiendo de lo demás, nos ceñimos al mérito intrínseco de estas obras, yo las trocaría todas por un buen quadro de Rafael» (251), al contrario que ocurre con la escultura o con la arquitectura.

Defectos similares son achacados a los primitivos italianos, que en el siglo XVIII son vistos, por lo general, más como curiosidades históricas que como valores artísticos. Nos puede servir de muestra el juicio que le merecen las delicadas pinturas al fresco del Giotto en la Iglesia de la Anunciata de Padua: «frialdad, timidez, ningún artificio en grupos, actitudes ni luzes; algunos ropages no carecen de mérito; allí se ve la infancia del arte, qué distancia inmensa desde aquella ruda imitación de la naturaleza a la Aurora de Guido [Reni]; Giotto fue admirado en su tiempo como un prodigio, y no sin razón, ¿quién sabe cómo empiezan las artes, ni quién sabe tampoco hasta qué punto puede llevarlas el talento humano?» (399). Si se trata de obras al fresco, Moratín no tiene inconveniente de dar la razón a los que consideran la mejor a la Batalla de Constantino y Maxencio ejecutada por Julio Romano: «mucha invención, mucho movimiento, excelentes grupos, expresión, valentía y franqueza de pincel» (338).

Moratín aplica la retórica descriptiva de la écfrasis, en una elaboración lingüística ya forjada por la tradición. Al igual que en la escultura, aprecia en la pintura la viveza y el dramatismo en la expresión y el movimiento, a las que une la armonía en la invención y composición, en el colorido y la luminosidad. Estos criterios son los que le llevan a describir y alabar, por ejemplo, la Madonna de San Girolamo, de Correggio:

El famoso quadro de Correggio, donde representó a la Virgen con el Niño, San Gerónimo, La Magdalena y un ángel, encanta, me parece justa la crítica que se ha hecho de que el niño no tiene dignidad; es cierto, aquel niño no es una divinidad; es un chiquillo como todos los demás; pero qué viveza tiene, qué inquietud, cómo quiere enrredar con las hojas del libro de San Gerónimo, que le presenta el Ángel, mientras con la otra manecilla agarra los cabellos de la Magdalena. Qué complacencia muestra la Virgen, la Magdalena qué amor afectuoso y reverente. El Ángel, cómo se ríe; este quadro está lleno de gracia y expresión, y tiene tal frescura de colorido, que a cierta distancia parece que acaba de salir de las manos de aquel gran artífice. (179)

O el Judit y Holofernes, de Caravaggio (entonces expuesto en la Galería del Conde Zambeccari, Bolonia), que le impresionó sobre todo por el sensible patetismo de la escena que representa (y que relaciona, interartísticamente, con la tragedia teatral), como a otros viajeros dieciochescos (el presidente de Brosses, por ejemplo: Viaje a Italia, carta XXII), aunque la memoria de Moratín se confunde algo en la posición de los personajes (de hecho, su descripción parece 
coincidir más, al menos en lo que respecta a la criada, con las dos versiones que del tema hizo Artemisia Gentileschi, conservadas en la Galería de los Uffizi de Florencia y en el Museo de Capodimonte en Nápoles, ambos visitados por Moratín):

vi el famoso quadro de Holofernes, pintado por Miguel Ángel de Caravaggio; terrible cosa por cierto. Judit le atraviesa la espada por el cuello; la cabeza, desgreńada, sangrienta, amoratada con las ansias de la muerte, da horror al verla. Judit muestra en su semblante el esfuerzo que la cuesta aquel hecho atroz; la criada que le está sugetando, grosera e insensible, solo se ocupa en oprimir con su fuerza varonil a aquel jayán temido. En este quadro, se manifiesta que el patético de la tragedia no se expresa menos con los pinceles que con la pluma. $(188)^{11}$

Cuando la pintura se acerca a la perfección en todas sus facetas, el máximo elogio de Moratín es la confusión de la ficción con la realidad, sobre todo en la aparente inminencia de su ejecución: ya lo hemos visto con la Madonna de San Girolamo de Correggio: «a cierta distancia parece que acaba de salir de las manos de aquel gran artífice» (179). También lo señala en la Virgen con el niño de Tiziano (Duomo de Padua): «parece dibujado por mano de las Gracias» (395); en su Dánae y la lluvia de oro, que "parece la verdad misma» (270); o en un gran óvalo de Veronés en el Palacio Ducal de Venecia, el cual "parece que acaba de pintarse» (460).

Consecuentemente, como en el resto de manifestaciones artísticas, rechaza todo aquello que rompe o distancia de la ilusión de verdad. Así, el anacronismo en las vestiduras o en la introducción de personajes contemporáneos al pintor («En la Scuola grande de la Carità [de Venecia] hay otro quadro del Tiziano, cosa de gran mérito; representa la purificación, entre los personages retrató a algunos de su tiempo, con el mismo traxe que usaban; defecto que he visto mui repetido en los pintores más acreditados», 463; "Esta idea, de un Cristo, una Virgen, o un Santo en la gloria, y un Dux a los pies rezando letanías, está tan repetida [...], que fastidia al que lo ve», 458-459); la falta de adecuación o propiedad en la expresión (Dánae y la lluvia de oro de Tiziano: «Acaso hubiera debido dar al rostro de Danae otra expresión; toda la figura anuncia aquella dulce languidez de una posesión tranquila, pero no el éxtasis de las primeras delicias de amor, ni mucho menos la tímida sorpresa de una virgen que recibe en sus brazos a Jove tonante», 270; en la Iglesia de San Francisco de Génova, hay «un quadro de Andrea del Sarto en que representó la Adoración de los Pastores, pintó al Niño Dios metiéndose el dedo en la boca y tentándose la pollita. No puede darse cosa más natural ni más graciosa en un chiquillo, ni más impropia de la alta magestad del Divino Verbo», 505), y lo que él llama, por contagio teatral, el pecar contra la unidad de acción, es decir, el introducir

11. Es un tema que sin duda excita la imaginación de Moratín: en el palacio de Windsor ya le había parecido «notable» la versión pictórica de Judith y Holofernes a cargo de Guido Reni (Apuntaciones sueltas de Inglaterra, II, 8, ms. 5891 BNM, fol. 39r; en Obras completas de Nicolás y Leandro Fernández de Moratín, cit., II, p. 962), y en el cuaderno 8.1 del Viaje a Italia volverá a acordarse del «terrible Holofernes de Caravaggio» (585). 
varias secuencias en un mismo cuadro (como hizo Rafael en la Liberación de San Pedro: «El quadro de San Pedro libertado de la prisión por un ángel, peca de la unidad de acción", 339; o Veronés en El rapto de Europa: "peca contra la unidad de acción [...] Si todos los esfuerzos de la pintura van dirigidos a hazer parecer verdad lo que es mera ficción, ¿cómo puede ser verdad que un mismo personage se vea repetido tres vezes a un tiempo?», 458).

Sin embargo, estos defectos no tienen tanta importancia cuando la pintura es verdaderamente valiosa: en el Palacio de Turín hay "otro gran quadro, de Pablo Veronés, que representa a la Infanta de Egipto haciendo sacar del río al niño Moysés, entre las damas egipcias se ve un personage vestido con su ropilla y su capa negra, su gorguera y pelón, pero ¿qué importa si el quadro es excelente?» (529-530).

Finalmente, en cuanto a la pintura contemporánea Moratín escribe que «ni puede citarse un quadro moderno de gran composición, capaz de sostener el antiguo honor a que llegó la pintura en Italia, ni consolar, por lo menos, a los que advierten su general decadencia en Europa» (585).

Al margen del análisis individual de las principales artes, Moratín realiza de vez en cuando juicios de lo que podíamos llamar estética interartística, donde relaciona principalmente la pintura con la literatura, como ya había hecho con las caricaturas inglesas ${ }^{12}$. El establecimiento de correspondencias entre ambas formas de arte era un lugar común desde Horacio, y adquirió un gran desarrollo en los Siglos de Oro. A veces estos paralelismos son demasiado amplios y vagos, como cuando compara los defectos que puedan achacarse a Rafael con los de Homero o Cervantes, en virtud de la grandeza su arte (338-339), o cuando, para ponderar el progresivo placer que provocan las obras más bellas, escribe que «estos mismos efectos produce un idilio de Theócrito comparado con una égloga de Virgilio, una comedia de Terencio con una del afluente, pomposo y extravagante Calderón; una figura de Rafael con la Magdalena de Le Brun; la Venus de Médicis con qualquiera estatua del Bernini» (247).

Sin embargo, la mayoría de comentarios de este tipo le sirven a Moratín para denostar tanto el arte como la literatura barroca; de este modo, Bernini suele ser el equivalente de Villamediana, Góngora o Calderón, juzgados como artífices llenos de ingenio y talento, pero también como grandes corruptores de las $\operatorname{artes}^{13}$. En Venecia, escribe Moratín,

Vi en las obras de este siglo un gusto berninesco enteramente opuesto a la hermosa sencillez de la naturaleza, con todos los defectos propios de aquel estilo, y ninguno de los primores que se admiran en el célebre Bernini. Este artífice, como todos los grandes corruptores de las artes, tenía un talento extraordinario, y en fuerza de él produxo

12. L. Fernández de Moratín, Apuntaciones sueltas de Inglaterra, I, 20, ms. 5891 BNM, fols. 17v-18v; Obras completas de Nicolás y Leandro Fernández de Moratín, cit., II, pp. 942-943. Vid. R. Alarcón Sierra, "Las Apuntaciones sueltas de Inglaterra...", art. cit.

13. En la Biblioteca Nacional de Madrid se conserva un breve apunte de L. Fernández de Moratín sobre Calderón de la Barca, ms. 12.963 (22), editado en Obras completas de Nicolás y Leandro Fernández de Moratín, cit., II, p. 1350. 
obras llenas de belleza y de extravíos, lo mismo hizieron Marini, Góngora, y Calderón en la poesía; pero como los que se dieron a imitarlos carecían del raro talento de sus maestros, solo pudieron copiar sus desaciertos, no sus perfecciones (455-456)

En Turín, la Iglesia de San Lorenzo es «todavía más extravagante que la primera [la Capilla de la Catedral]; alaben, si quieren, el ingenio del artífice, como tal vez se alaba el de Villamediana y Góngora, pero el juizio no hay para que nombrarle» (520). En otras ocasiones, las correspondencias se basan en algún paralelismo menos general entre las artes: «Yo creo que el estudio de las luzes y el colorido en la pintura equivalen al estilo y dicción poética; de nada sirve un buen plan, lleno de invención y corrección, si le acompaña un estilo duro y tenebroso como el de Villamediana y Silveira» (318-319). Finalmente, a veces Moratín concreta todavía más y señala el mismo fallo en una obra pictórica que en una literaria; por ejemplo, en la composición del Encuentro entre León el Grande y Atila, de Rafael, «se nota el defecto de que siendo aquel rey el personage principal, ocupa un segundo término», a lo que añade: «En el poema de la Jerusalén de Lope, se ve igual defecto» $(338)^{14}$.

La consideración de la antigüedad clásica en el suelo italiano era un tema caro al humanismo que no faltaba en ningún libro de viajes. El procedimiento común era comparar los lugares con sus referencias mitológicas, históricas y literarias, lo que también va a hacer Moratín: la evocación del ayer tiene en la imaginación del viajero más fuerza sugestiva que el paisaje real observado. Sin embargo, en el siglo XVIII, con las excavaciones en Pompeya y Herculano, otra dimensión se abre en los alrededores de Nápoles: ya no es, como en el resto de Italia, la ruina clásica yuxtapuesta a otras manifestaciones artísticas y a otros siglos, sino la antigüedad completamente preservada por el hecho mismo de su destrucción.

Gracias a ello, toda la región de Nápoles es interpretada por Moratín como una verdadera ruptura en el espacio y en el tiempo con el momento presente. Hasta su estilo cambia, y de forma quizá única en todo su viaje, se hace especialmente elevado y poético. En su descripción, utiliza con abundancia la repetición, el paralelismo sintáctico y de tiempos verbales y la anáfora de formas deícticas, con la virtud de establecer la ilusión óptica de que narrador y lector se encuentran en el texto cara a cara con lo observado, y de crear un ritmo casi de letanía y un tono austero, que introduce los vestigios del presente en la plenitud del ayer, la mortalidad del hombre frente a la inmortalidad atemporal del lugar, como si hubiera dejado de estar habitado desde hace solo unas horas:

No es posible caminar por aquel parage sin una especie de entusiasmo que todos aquellos obgetos inspiran. Éste era el theatro; aquí se acomodaba el pueblo, allí la nobleza; por allí salían los actores; aquí se oyeron los versos de Terencio y Plauto; este recinto sonó con aplausos públicos, los hombres desaparecieron y el lugar existe. Éste era el templo, allí está la inscripción, allí las aras; las paredes anuncian todavía en

14. En la Biblioteca Nacional de España se conservan unas «Apuntaciones sueltas sobre algunas comedias de Lope de Vega» de L. Fernández de Moratín, ms. 18.666 (10); vid. Obras completas de Nicolás y Leandro Fernández de Moratín, cit., II, pp. 1318-1320. 
pinturas y estucos, los atributos de la deidad. Aquí se degollaban las víctimas; aquí, escondidos los sacerdotes, prestavan su voz a un mudo simulacro, y el pueblo, lleno de terror, creía escuchar la divinidad misma, anunciando a la ignorancia humana los futuros destinos. Ésta es una calle, empedrada está como las de Nápoles, con lavas que ha vomitado ese volcán vecino, a un lado y otro hay ánditos para que pase el pueblo seguro de los carros, aún se ven las señales de las ruedas. Veis aquí las tiendas, allí se vendieron licores; la insignia que está a la puerta, la señal que ha dejado el pie de las copas sobre el mostrador, y las hornillas inmediatas para tener caliente la bebida lo manifiestan. Allí hay otra donde se vendían príapos, la insignia está esculpida sobre la puerta, allí está el aparador, repartido en gradas, donde se exponían estos dijes a la vista pública. Éstas son casas de gente rica, éste es el pórtico, sostenido en columnas de ladrillo revestidas de estuco, con decoración dórica; allí está el patio, con la galería que le rodea; estancias pequeñas, altas, con mosaicos en el suelo y pinturas en las paredes; el baño, la estufa, con pared hueca, por donde se comunicaba el calor; el jardín, la fuente, la bodega con grandes cántaros, la sala de combersación, la de comer, la alcoba, el poyo donde estaba el lecho; pinturas voluptuosas por todas partes, triunfos de amor. Veis allí los sepulcros que erijió la patria agradecida a sus hijos ilustres, la inscripción anuncia sus nombres y su calidad, allí reposan sus cenizas. Qué silencio reina en todo el contorno. Qué soledad horrible. Y todavía el Vesuvio arroja llamas y retumban sus cavernas con rumor espantoso. (254-255)

El párrafo tiene una calidad sugestiva excepcional. Es una forma de revivir el pasado que a un lector contemporáneo le resultará paradójicamente cercana a la practicada por Azorín. A continuación, el viajero, tras haber reconstruido la vida de Pompeya a través de sus vestigios, los destruye y los sumerge de nuevo en el tiempo mediante la recreación sublime de una erupción del Vesubio, como un nuevo Plinio ${ }^{15}$.

En su recorrido, el viajero va a seguir evocando el pasado, en una correspondencia continua del paisaje con la leyenda, la historia y la literatura: las posesiones de Sannazaro en Mergelina y el epitafio de Bembo (263-264), el sepulcro de Virgilio sobre el monte de Possilipo (265), o la gruta de Puzol descrita por Séneca, atribuida a Virgilio y comentada por Petrarca (267). Tras una extensa descripción del Nápoles del presente, nuevamente se introduce Moratín en el ayer con su viaje a Pozzuolli y Bayas, «uno de los más interesantes para quien tenga alguna idea de la fábula y de la historia» (307). Ahora su inmersión se realiza en el paisaje irreal, casi utópico y ucrónico, de la mitología clásica: el lago Aganano, la Grota del Cane, las estufas de San Germán; la solfatara, donde los griegos localizaron la batalla entre Titanes y dioses, que Moratín describe como si esta realmente hubiera tenido lugar, y a la vista inequívoca de sus indicios:

Esta es la antigua Phlegra, aquí fulminó Júpiter a los gigantes, hijos de la Tierra; aquí fue la desigual porfía; aquí cayeron precipitados entre los montes soberbios que levantaban para escalar el Empíreo; aquí fue el destrozo horrible; tronó airado el hijo de Saturno, y perecieron los rebeldes Titanes. Aún se ven las ruinas espantosas; las

15. Para el tratamiento de la naturaleza en Moratín, vid. R. Alarcón Sierra, «Discurso, representación y mirada en el Viaje a Italia de Leandro Fernández de Moratín», art. cit., pp. 761764, y la bibliografía allí citada. 
montañas quebrantadas y abiertas, las cenizas, el humo, el fuego mal extinguido, y el estruendo que se oye resonar en su concavidad profunda, nos recuerdan todavía la gran victoria. (309)

Tras visitar los templos de Augusto y de Júpiter Sérapis, el pedestal de Tiberio y la casa de Cicerón (309-311), una nueva inmersión en el mundo mitológico se produce al bajar al lago Averno, virgiliana entrada a los infiernos, y a la gruta de la Sibila, «habitación espantosa» ante cuya sugestión Moratín justifica las visiones en otros tiempos de una fantasía desatada:

Si la Sybila invocaba en ella los Manes, o daba desde aquellos senos profundos equívocas respuestas, no es de admirar que la fantasía acalorada con las ideas de religión y conturbada por el terror que tal lugar inspira, creyese mirar presentes los senos del abismo, oyese cruxir las ruedas y máquinas de sus tormentos, bramar los monstruos y viese vagar sin descanso las sombras pálidas y sacudir sus antorchas las implacables furias, ceñida su frente de irritadas vívoras. (313)

Cuando Moratín sale de este mundo legendario, graduado desde su fiel reconstrucción mitológica a la justificación racional, ya no le queda sino observarlo a distancia y, libre ya de la sugestión que le ha producido, constatar al modo clásico, en un tono poético y elevado, su definitivo hundimiento en el tiempo, vencido por una naturaleza que ocupa los ecos del pasado:

Toda la costa de Bayas fue en otros tiempos un país de delicias, de opulencia y luxo [...] Ya no existen ni los palacios, ni los baños deliciosos, ni los templos, ni los jardines, ni los sepulcros; las ciudades populosas desaparecieron; todo es destrozo y ruinas; las higueras y tenaces yedras y ásperos arbustos crecen entre los mármoles quebrantados (314)

Por toda esta costa estubieron los palacios de Pompeyo, los de Julio César, Mario, el facundo Hortensio, Julia Mammea, Pisón y los del voluptuoso Lúcullo, en los quales murió Tiberio; el mar rompe sus ondas con estruendo, en las ruinas dispersas que coronan su orilla, y los pezes, mudos, desovan en las estancias de tantos trastornados alcázares. (316)

Pocos viajeros dieciochescos describieron la antigüedad clásica de Nápoles con la gradación y diversidad tonal y sentimental con que lo ha hecho Moratín. Lo acostumbrado era desplegar toda la erudición clásica a través de citas literarias que iban de Virgilio a Petrarca, procedimiento plenamente satisfecho por Addison en sus Remarks on several Parts in Italy, pero no tanto revivir aquel mundo perdido con la intensidad con que lo hace suyo nuestro narrador, $y$ a la vez pertrechado, por otra parte, con las mínimas referencias posibles.

En otras ciudades italianas, la antigüedad clásica es descrita de un modo muy distinto. El punto de vista del viajero señala la yuxtaposición y el heterogéneo contraste de épocas reunidas en una sola visión, e incluso en un mismo edificio. Pese a ello, Moratín señala que todavía perdura un «ayre de magnificencia» que «no ha perdido del todo el carácter grandioso». Lo que ya es más difícil es conseguir la plena inmersión en el pasado que hemos presenciado en Nápoles. Por contra, lo que ahora se pone de manifiesto es el contraste entre unos tiempos gloriosos y un 
presente degenerado. Por ejemplo, en la Arena de Verona, «quando yo estube, oý a el vulgo los despropósitos de Arlequín donde otro vulgo oyó bramar las fieras y el gemido de los gladiatores moribundos» (381-382); o en la Sala della Ragione de Padua, donde «hay otro Tito Livio, que, a pesar de la inscripción que tiene debaxo, me pareció una Santa Theresa; esta galería es el cagatorio general de los pillos que se anda hartando de ubas por la plaza, en ninguna parte se sufriría tal indecencia» (397).

En Roma, solo se salvan parcialmente de esta carcoma los obeliscos egipcios y las columnas romanas. Los obeliscos representaban todavía en el siglo XVIII un triple misterio: el de su edad y origen, el de su función y el de sus jeroglíficos, "que nadie ha entendido ni entenderá», como el mismo Moratín manifiesta (346), y que «dan una grande idea de la cultura y la opulencia de los egipcios» (348). Winckelmann ya se había referido a las alegorías egipcias en sus Reflexiones sobre la imitación de las obras griegas en la pintura y en la escultura (1755), y la primera gran exploración sistemática de su cultura es llevada a cabo precisamente a finales del siglo XVIII, por el grupo de científicos que acompañaron a Napoleón en su expedición militar a Egipto. Sin embargo, nuestro viajero ironiza sobre la banalidad de su tiempo cuando escribe: «en quanto a sus misteriosos geroglíficos, me remito a un alemán que vive en la Calle del Babuino, y jura y perjura que los entiende y promete publicar un libro en folio, en que explicará una por una las figurillas que los adornan. Dios le dé acierto, y a nosotros gracia para servirle y buen apetito» (348). Efecto análogo de brutal contraste entre pasado y presente encontramos en su descripción de las columnas romanas, cuando, tras describir los triunfos que representan, anota sumariamente: "Al pie de esta gran columna [Antonina] vive un barbero que tiene la llave de la escalera, la de la Columna Trajana está en poder de un sastre» (350).

\section{Conclusiones}

Como hemos podido comprobar en este sintético análisis, las anotaciones que Leandro Fernández de Moratín realiza en su Viaje a Italia sobre la vida cultural italiana, las antigüedades clásicas y obras de arte, tienen un gran interés. Los libros de viaje contribuyen a asentar, en el siglo XVIII, una crítica de arte diletante en escritores que no eran especialistas en la materia, por lo cual deben ser tenidos muy en cuenta. Moratín asume los ideales normativos de la estética neoclásica (la imitación del arte grecolatino en arquitectura y escultura, y del renacentista en pintura), pero también ofrece juicios de gusto e impresiones personales que caracterizan a su yo textual.

Según expone en sus diarios de viaje, el objeto del arte es la imitación de la naturaleza, pero no de forma directa sino idealizada, no tal cual es sino tal y como debería ser (idea clásica de la imitación de la naturaleza y de la belleza). El arte debe provocar la ilusión de que parezca la verdad misma. Para discernir su mérito, hay que analizar las ideas la imitación, invención y belleza. El 
carácter de las mejores obras es sencillez, hermosura y verdad. Al aplicar estos criterios a las manifestaciones artísticas concretas, todo resulta mucho más complejo. La necesidad de motivar sus gustos hace que el yo textual adquiera un gran relieve. La descripción suele ir acompańada de una evaluación, que retrata social e intelectualmente a su emisor. Pero, además, la crítica de arte de Moratín está cargada de manifestaciones afectivas, cuando rechaza o admira la obra que describe, lo que propicia una extraversión de los sentimientos y una apariencia de confianza hacia su hipotético lector. En su rechazo, emplea un tono informal y distendido, lleno de rasgos coloquiales y hasta vulgares, humorísticos o irónicos. Cuando alaba, se aproxima a la expresión sensible de lo poético, lo espiritual o lo verdadero.

En arquitectura, la antigüedad romana es el modelo, por sus valores de simetría, proporción, armonía, ligereza, sencillez, orden, sobriedad, elegancia, belleza y utilidad.

Todo lo que no cumple estas normas es rechazable, tanto el gótico como el barroco, entendidos como desviaciones del buen gusto, términos de significación peyorativa que designan un conjunto de obras que no cumplen las reglas.

En escultura, además de los modelos griegos, aprecia en Antonio Canova la estética de la inminencia del movimiento y la expresión: el engaño y la ilusión de los sentidos, según el cual las figuras parece que están vivas, que son reales y que van a moverse de un momento a otro. En pintura, admira la viveza y el dramatismo en la expresión y el movimiento, a las que une la armonía en la invención y composición, en el colorido y la luminosidad. Cuando la pintura se acerca a la perfección en todas sus facetas, el máximo elogio de Moratín es la confusión de la ficción con la realidad. Consecuentemente, rechaza todo aquello que rompe la ilusión de verdad: los anacronismos, la falta de adecuación o propiedad en la expresión, o el introducir distintas secuencias en un mismo cuadro. También son de gran interés los juicios interartísticos que Moratín realiza, donde relaciona la pintura con la literatura, lo que le sirve principalmente para denostar tanto el arte como la literatura barroca (pese a su significativo interés por el Judith y Holofernes de Caravaggio, muestra del gusto sensible de las últimas décadas del siglo XVIII).

En su recorrido por la región de Nápoles, el viajero realiza, con gran sensibilidad, una plena inmersión en el pasado, en una correspondencia continua del paisaje con el mito, la historia y la literatura. Pocos viajeros dieciochescos describieron la antigüedad clásica de Nápoles con el acierto, la gradación y diversidad tonal y sentimental con que lo hace Moratín. En otras ciudades italianas, la antigüedad clásica es descrita de un modo muy distinto: señala la yuxtaposición y el heterogéneo contraste de épocas reunidas en una sola visión, e incluso en un mismo edificio, poniendo de manifiesto el contraste entre unos tiempos gloriosos y un presente degenerado.

Por encima de todo ello, destaca la prosa, ágil, vivaz e innovadora de un diario de viaje no destinado a la publicación (una representación privada de lo público, frente a su teatro, una representación pública de lo privado). A las 
normativas neoclásicas sobre el arte y a las que conlleva la escritura de un viaje, Moratín sobrepone su aguda capacidad de observación, su sentimiento, su goce y su juicio personal. Ello se plasma en una escritura desenvuelta, libre y variada, que se desplaza del tono normativo e ilustrado al irónico y humorístico. El hecho de que se trate de la escritura abierta de un diario de viaje, que se construye sobre la marcha, explica en parte la libertad e interés de sus observaciones. Es la curiosidad moratiniana por todo lo que le rodea y su maestría y fluidez verbal la que consigue impregnar su discurso de una viveza y un dinamismo que hace que podamos hablar de ella, en sus mejores momentos, como de una escritura plenamente moderna. 